\title{
The Informational Content Of Changes In Stock Recommendation: Chaebol Vs. Non-Chaebol Affiliated Analysts
}

Youngtae Yoo, Incheon National University, Korea Hyunjun Park, Incheon National University, Korea

\begin{abstract}
Accurate analysts' reports alleviate information asymmetry between companies and investors by providing accounting information that is useful in investment decision-making for market participants. Investors evaluate the credibility of stock recommendations based on the accuracy of the earnings forecasts of analysts, applying them in the decisionmaking process. Studies of stock recommendations have focused on their informational content, systematically analyzing the characteristics of recommendations and, to a lesser degree, decision-making factors. For most analysts, when stock recommendations and forecast changes are simultaneously disclosed, a large bias results if analysts fail to consider the magnitude of the market reaction relative to the earnings forecast and stock recommendations. In most previous studies, the informational content of both individual stock recommendations and changes in stock recommendations was investigated. In this study, we examine differences in the informational content depending on the stock recommendations of the report released immediately previous to the current report for the same recommendation. An upgraded (or downgraded) revision within the same recommendation category is associated with a greater (lower) stock price return. Even the same recommendation in the market may cause different reactions depending on both the recommendation itself and on the direction of change of the recommendation. Affiliated analysts have more access to inside information of the companies they analyze. The stock returns after revisions of Chaebolaffiliated analysts are significantly higher than those of non-Chaebol-affiliated analysts.
\end{abstract}

Keywords: Stock Recommendation; Analyst Forecast; Market Reaction; Chaebol-Affiliated Analysts; Financial Structure

\section{INTRODUCTION}

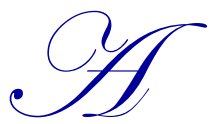

nalysts release accurate data in order to alleviate information asymmetry between companies and investors and to provide useful accounting information for investment decision-making of market participants. Investors may evaluate the credibility of stock recommendations based on the accuracy of the analysts' earnings forecasts that are utilized in the decision-making process. Several Korean and international studies agree that achieving high accuracy is analysts' primary mission. Various researchers have therefore investigated the forecasting accuracy of analysts, identifying factors that affect the informational content of earnings forecasts and forecast accuracy. Recent Korean studies have investigated the effects of analyst- and firm-level characteristics on earnings forecast accuracy.

Studies of stock recommendations have focused on their informational content, systematically analyzing the characteristics of recommendations and, to a lesser degree, decision-making factors. For most analysts $(90.90 \%)$, when stock recommendations and forecast changes are simultaneously disclosed, a large bias results if analysts fail to consider the magnitude of the market reaction relative to the earnings forecast and stock recommendations. When analysis of the market reaction to analysts' reports reveals positive unexpected earnings, this change must be distinguished from a market reaction due to a positive earnings forecast or an upward change in stock recommendation. In most previous studies, the informational content of both individual stock recommendations and changes in stock recommendations was investigated. In this study, however, we examine differences in the informational content 
depending on the stock recommendations of the report released immediately previous to the current report for the same recommendation. About $70 \%$ of the stock recommendations by analysts are found to be "Buy" or "Strong Buy." By contrast, "Sell" and "Underweight" recommendations account for just $1 \%$ of the total. Thus, a bias in stock recommendations may exist. In this situation, even the same "Buy" recommendation in the market may cause different reactions depending on both the recommendation itself and on the direction of change of the recommendation (upward, downward, or status quo).

\section{RELATED RESEARCH AND HYPOTHESES DEVELOPMENT}

\subsection{Related Research}

Stock recommendations themselves represent informational content in the capital market (Kim and Eum, 2006). Financial analysts provide investment recommendations by collecting comprehensive data about the intrinsic value of companies. The past studies verified whether analysts' stock recommendations display information conctents when investments based on the recommendations deliver abnormal return.

Womack (1996) and Elton et al. (1986) hypothesized that when analysts assign a buy recommendation or make upward revisions in recommendation grade of a company, abnormal return is expected in the next six months. Additionally, Barber et al. (2001) showed that it is possible to earn high investment returns with analysts' consensus on recommendation grades of a firm by creating the portfolios which include buy-rated stocks and sell-rated stocks, exclusively. In Korean domestic studies, Kim and Eum (2006) confirmed the effects of changes in stock recommendations and target stock prices on the actual stock prices. It was found that such changes had been already reflected in the actual stock prices, and recommendation changes exert much greater influence on the stock prices. In addition, Jeong and Lim (2005) showed that there were differences in CAR (cumulative abnormal return) depending on analysts' stock recommendations and the direction of expected returns. They also noticed a high level of CAR when there are rises in both buy recommendations and expected returns. In the end, international and Korea domestic studies both revealed that utilization of stock recommendations have a significant reaction on stock prices at the time of public announcement. This suggests that investors can use analysts' reports as a strategic indicator to determine whether to buy, hold or sell a stock. Furthermore, there have been studies about whether consensus information about investment recommendations can be the means to achieve CAR (Lee and Choi, 2003; Jegadeesh and Kim, 2010). The consensus of stock recommendations is the numerical average of recommendations assigned to a firm during a specific period. And Jegadeesh and Kim (2010) showed that it is possible to yield CAR through portfolio creation, which utilizes the value of consensus, but it was concluded that the returns were not so significant if the expected returns and probable variables were extracted. According to Kho and Kim (2007), when forming a portfolio that utilizes the consensus of buy and sell recommendations in the capital market, no CAR was delivered. They further pointed out that with the buy recommendations, there have been conflicting interests between analysts and firms over the maintenance of business partnership. When the prevailing view is to buy stocks, investment recommendations may have no additional information effect. However, if they are ferreting out the genuine buy and sell recommendations by controlling quality attributes of investment recommendations, it would be possible for consensus information to have an additional value. Yoo and Kang (2015)'s study revealed the decisive factor of 'No Response' recommendation and proved its information contents. The previous studies on stock recommendations mostly focused on the information effect of recommended grades and changes in grades, and consensus. In this study, the effects of revision within the same recommendation category are investigated. Section 2.2 presents the hypothesis for this study along with a more detailed explanation of the situation in the Korean capital market.

\subsection{Hypothesis Development}

Currently, analysts' stock recommendations in the Korean capital market are greatly biased toward "Buy" recommendations. Table 2 presents the percentages of individual stock recommendations. This bias toward "Buy" may cause a conflict of interest in the relationships between analysts and the companies they analyze in the capital market. Bias may also be caused by a decline in reputation due to a forecast error. This decline is greater when a "Sell" recommendation is disclosed compared to the situation when a "Buy" recommendation is disclosed. In circumstances of considerable fluctuation in the capital market, if "Buy" remains the major recommendation, market participants 
may not perceive it as significant. At the same time, a continuous "Sell" recommendation may be perceived as a serious signal that causes a negative market reaction in the short and long terms. As can be seen in the table, the "Hold" recommendation accounts for only $26 \%$ of all recommendations. Investors may recognize a "Hold" recommendation as a negative recommendation, which may result in excessive trading volumes and a negative abnormal return. Thus, individual stock recommendations may have different informational content, and the quality of the information may differ from one recommendation to another.

Table 1. Stock recommendations

\begin{tabular}{|c|c|}
\hline Recommendation & Ratio (Unit: \%) \\
\hline Strong Buy & 0.76 \\
\hline Buy & 67.08 \\
\hline Hold & 26.51 \\
\hline Underweight & 0.95 \\
\hline Sell & 0.15 \\
\hline
\end{tabular}

When the "Buy" and "Hold" recommendations make up the absolute majority of all recommendations, investors may pay attention to the direction of change in stock recommendations. For example, a "Buy" recommendation may have more informational content than that of other "Buy" recommendations if the immediately previous recommendation was "Hold." On the other hand, an unchanged "Buy" recommendation may have a negative informational impact if it was changed downward from "Strong Buy" to "Buy."

Beaver (1968) explained investment information from two angles. First, investment information changes the investor's expectation of the result of an event. If new information changes investors' evaluations of future profit distribution, it has informational content. Market expectations are formed according to future earnings distribution forecasted by investors, and a new equilibrium stock price is formed in the market. However, because a gap exists between the forecast value of the investors and the intrinsic value of the company, the interpretation of the forecast may differ among investors. In this situation, buyers and sellers may be active at the same time, resulting in great fluctuations in trading. Second, stock information should not only change investors' expectations of future stock returns, but also lead to a change in their actions. If it is assumed that the trading of stocks changes the optimum portfolio of investors, and that analysts' reports accurately reflect market expectation values, the informational content of the stock recommendations can be verified by observing the abnormal return on the day of disclosure. Therefore, the following hypothesis is put forward.

Hypothesis 1: Even the same stock recommendations may have different informational content depending on the direction of change in the recommendation (upward or downward).

Generally, financial analysts publish reports and receive performance evaluations from brokerage firms where they work. Thereupon, they could have better access to confidential information if the brokerage firm they work for and the companies they cover are affiliated under the same business group (Chaebol affiliated). For this reason, the market response is greater when analysts at the Chaebol affiliates assign stock recommendations on a company, which is affiliated under the Chaebol. However, at the same time, the company may expect analysts to publish more positive recommendations, triggering conflict of interests between the firm and analysts. In the latter case, the market would show no or negative reactions to the recommendations. Thus, the second hypothesis is stated as a null hypothesis.

Hypothesis 2: There is no difference between Chaebol and non-Chaebol affiliated analysts' recommendation changes. 


\section{RESEARCH DESIGN}

\subsection{Variables}

\subsubsection{Cumulative Abnormal Return}

The calculation of CAR is as follows. This study utilizes a market-adjusted model, which benchmarked the market returns.

$$
A R_{i t}=R_{i t}-R_{m t}
$$

Where

$$
\begin{aligned}
& R_{i t}=\text { returns on a stock of an } i \text { company on } t \text { day, and } \\
& R_{m t}=\text { returns on a market portfolio on } t \text { day. }
\end{aligned}
$$

The following is the measurement of CAR based on abnormal return of sample enterprises calculated in the aforementioned formula.

$$
\operatorname{CAR}\left(t_{1}, t_{2}\right)=\sum_{t=t_{1}}^{t_{2}} A R_{t} \quad \operatorname{CAR}\left(\mathrm{t}_{1}, \mathrm{t}_{2}\right)=\sum_{\mathrm{t}=\mathrm{t}_{1}}^{\mathrm{t}_{2}} \mathrm{AR}_{\mathrm{t}}
$$

This will be utilized as a variable in the model designed to verify hypothesis 1 and 2 and prove whether changes in stock recommendations have an information contents. Assuming that the stock market ensures efficiency, stock prices contain all of the past and current information. Thus, this study offers an assumption that recommendations announced by analysts are fully and immediately reflected into the movement of a firm's stock prices. Thereupon, in an attempt to verify information contents through changes in returns on stock investments, this study conducted analysis for a relatively short period of verification time; $-1,0$ and +1 day.

\subsection{Up and Down Dummy Variables}

The variables that hypothesis 1 focuses on are $U p_{d u m}$ and $D o w n_{d u m}$ variables. As described in the previous chapter, stock recommendations are divided into five categories. To verify information content of recommendation changes, it is necessary to analyze the recommendations by categories. The definition of dummy variables is as follows.

$$
\begin{aligned}
& U P_{d u m}=1 \text { if the recommendation upgraded, } 0 \text { if not. } \\
& D o w n_{d u m}=1 \text { if the recommendation downgraded, } 0 \text { if not. }
\end{aligned}
$$

\subsection{Chaebol Affiliation Dummy}

Chaebol groups are defined as affiliates, which belong to the top 30 business groups as defined by the Fair Trade Commission. Analysis activities of analysts are influenced by personal factors, including years of service and experiences in analysis of a specific industry and company. Other factors that affect their analysis include attributes of brokerage houses, interests with the company, and the firms' ownership structure and governance structure. Generally, analysts publish analysis reports and receive performance evaluations from brokerage houses where they work. Thereupon, they could have better access to confidential information if the brokerage house they work for and the companies they cover are affiliated under the same business group. For example, an analyst at Samsung Securities would have more access to information on Samsung Electronics. This is deemed as replacement of information environment and the variable ChaeAff dum is defined as follows. 
ChaeAff dum $=$ when an analyst assigns reports on a chaebol affiliated company to which his or her brokerage house belongs, it is described as 1 . If not, it is described as 0 .

\section{2. Regression Analysis Model}

In order to verify hypothesis 1 mentioned above, this study states multiple regression analysis as follows. The independent variables $U p_{d u m}$ and $D o w n_{\text {dum }}$ are used to verify changes in stock recommendation. The study model and the individual control variables are defined as follows:

$$
\begin{aligned}
& C A R_{(-1,1)}=a_{0}+a_{1} U p_{d u m}+a_{2} D_{0 w n_{d u m}}+a_{3} M V+a_{4} L E V+a_{5} R O E+a_{6} N G E+a_{7} \text { BETA } \\
& +a_{8} \text { Coverage }+a_{9} D \_E P S+a_{10} D \_P R I C E+a_{11} K O S P I+e
\end{aligned}
$$

The major financial attributes include $M V, L E V, R O E, N G E, B E T A$ and Coverage, which were utilized in the past studies. The inclusion of $M V$ is to control influence of companies' information environment on returns on stock investments (Collins and Kothari, 1989). The inclusion of $L E V$ in control variables is to control the situation where disclosed information of a company with a high level of $L E V$ has little or no impact on returns on stock investments (Aboody et al., 1999). As for $M V$ and $L E V$, study results conflict with each other, so this study did not predict the expected impact on the market response. $N G E$ is included to reflect the past studies indicating that account benefits show qualitatively different patterns depending on whether the benefits are in the positive or negative territories (Hayn, 1995). BETA, which was drawn, based on the monthly returns on stock investments, is a variable measuring the level of risks associated with a company. The higher BETA is, the higher uncertainty is surrounding the expected returns of a company, leading to a smaller response to stock prices, and so negative regression coefficient is expected (Kim et al., 2013). Whether the analyst service is provided for a company depends on the cost of information supply and the amount of benefit. The better the information environment is, the more efficiently information is reflected to generate a great market response in the short-term. $R O E$ is the indicator, which measures how much profit, a company earned in comparison to the total amount of shareholder equity, and it was added as a variable, which controls returns of a company. Like the model for hypothesis 1 , in order to control the movement of expected returns and expected stock prices, this study utilized variable ratio in comparison to each predictive value.

\section{2. Sample Description}

This study analyzed the data between 2000 and 2010 and the criteria of the analysis are as follows. The sample companies were selected from those whose financial data were provided through KIS-VALUE, and are required to meet the following conditions.

1) Public announcement of investment recommendations made by analysts

2) The major bourse KOSPI and junior bourse KOSDAQ-listed companies

3) Companies irrelevant to the financial sector including banking, insurance and brokerage services

4) Companies not suffering from capital erosion

Condition 1 is to secure data necessary for the formation of a research model. Condition 2 is to obtain sample companies, which are actively being traded in the capital market. Condition 3 is to provide comparative analysis through samples falling into the same category of industry. The financial sector differs from the non-financial sector regarding the form of financial statements, and compared to other sectors, it is under the unique economic environment, which involves complex regulations. As for Condition 4, financially distressed companies including those suffering from capital erosion should be excluded because they make it difficult to gain an accurate understanding of the situation. Analysts' reports and firms' financial information were collected from Data-guide-Pro and KISVALUE. Taking those into consideration, a total of 328,534 analysts' reports-firm-year data were selected. 


\section{RESULTS}

\subsection{Descriptive Statistics}

The descriptive statistics are shown in Table 2. This table presents mean, median, standard deviation, minimum, and maximum values. The observation period is from 2000 to 2010 . All key variables are described herein. It found that the entire sample firms' average of $C A R_{(-1,1)}$ reached 0.0020 while $U p_{\text {dum }}$ and $D o w n_{\text {dum }}$ stood at 0.0202 and 0.0236 , respectively, indicating the portion of upgrade recommendations and downgrade recommendations in the total. The average of $M V$ was valued at 27.6018, that of $L E V 2.0847$, and that of $R O E 0.1134$. The average of $N G E$ reached 0.0893 , showing that 8.93 percent of the entire samples were in the red. The average of BETA was at 0.9703 while the average of Coverage was estimated at 20.6916, indicating that an average of 20 analysts give recommendations to a company. The average of $D_{-} E P S$ and $D_{-} P R I C E$ was -0.0055 and 0.0071 , respectively, while the average of KOSPI was 0.7754 , showing that about 78 percent of samples are KOSPI-listed firms.

Table 2. Descriptive statistics

\begin{tabular}{|c|c|c|c|c|c|c|}
\hline Variables & $\mathbf{N}$ & Mean & StdDev & Minimum & Median & Maximum \\
\hline$C A R(-1,1)$ & 328,534 & 0.0020 & 0.0557 & -0.2351 & 0.0001 & 0.2579 \\
\hline$U P_{d u m}$ & 328,534 & 0.0202 & 0.1407 & 0 & 0 & 1 \\
\hline Down $_{d u m}$ & 328,534 & 0.0236 & 0.1518 & 0 & 0 & 1 \\
\hline ChaeAff dum & 328,534 & 0.0081 & 0.0898 & 0 & 0 & 1 \\
\hline$M V$ & 328,534 & 27.6018 & 1.8093 & 23.7973 & 27.4752 & 31.8272 \\
\hline$L E V$ & 328,534 & 2.0847 & 2.2761 & 0.1899 & 1.2370 & 13.9474 \\
\hline$R O E$ & 328,534 & 0.1134 & 0.1311 & -0.5620 & 0.1244 & 0.4059 \\
\hline$N G E$ & 328,534 & 0.0893 & 0.2852 & 0 & 0 & 1 \\
\hline BETA & 328,534 & 0.9700 & 0.3445 & 0.2026 & 0.9600 & 1.7901 \\
\hline Coverage & 328,534 & 20.6916 & 10.2209 & 1 & 21 & 46 \\
\hline$D \_E P S$ & 328,534 & -0.0055 & 0.1174 & -0.6034 & 0.0000 & 0.5124 \\
\hline D_PRICE & 328,534 & 0.0071 & 0.0711 & -0.2500 & 0.0000 & 0.3600 \\
\hline$\overline{K O} S P I$ & 328,534 & 0.7754 & 0.4173 & 0 & 1 & 1 \\
\hline
\end{tabular}

Table 3 shows the analysis of correlation coefficient of each variable and the numbers whose correlation coefficient is 0.4 and above is in bold type. According to the Pearson correlation analysis, CAR, a dependent variable, did not show a significant correlation with any variable. This suggests that a simple correlation may not be the reason if any meaningful outcomes are reported in the future. In the aspect of direction, it had a positive correlation with $U p_{d u m}$ and a negative correlation with Down dum , and as hypothesis 1 predicts, recommendation upgrades are expected to generate positive market response while recommendation downgrades are expected to garner negative market response. Additionally, it had meaningful connections with ChaeAff dum, albeit not a high correlation. This indicates that the finding of hypothesis 2 is that chaebol affiliated analysts would have advantages in terms of access to information. We examined whether there is multicollinearity among variables whose correlation is 0.4 or above in regression models. It was found that all variables had VIF value of five or below, suggesting that independent variables in the models do not have a serious problem regarding multicollinearity. 
Table 3. Pearson correlation coefficients matrix

\begin{tabular}{|c|c|c|c|c|c|c|}
\hline & $U p_{\text {dum }}$ & Down $_{d u m}$ & ChaeAff dum & $M V$ & $L E V$ & ROE \\
\hline $\operatorname{CAR}_{(-1,1)}$ & $\begin{array}{l}0.0217 \\
<.0001\end{array}$ & $\begin{array}{c}-0.0261 \\
<.0001\end{array}$ & $\begin{array}{l}0.0036 \\
0.0266\end{array}$ & $\begin{array}{l}0.0372 \\
<.0001\end{array}$ & $\begin{array}{r}-0.0079 \\
<.0001\end{array}$ & $\begin{array}{l}0.0228 \\
<.0001\end{array}$ \\
\hline$U p_{d u m}$ & 1 & $\begin{array}{r}-0.0223 \\
<.0001\end{array}$ & $\begin{array}{r}-0.0015 \\
0.3918\end{array}$ & $\begin{array}{r}-0.0100 \\
<.0001\end{array}$ & $\begin{array}{r}-0.0025 \\
0.1536\end{array}$ & $\begin{array}{r}-0.0149 \\
<.0001\end{array}$ \\
\hline Down $_{\text {dum }}$ & & 1 & $\begin{array}{r}-0.0045 \\
0.0095\end{array}$ & $\begin{array}{r}-0.0378 \\
<.0001\end{array}$ & $\begin{array}{l}0.0081 \\
<.0001\end{array}$ & $\begin{array}{r}-0.0266 \\
<.0001\end{array}$ \\
\hline ChaeAff dum $_{\text {dis }}$ & & & & $\begin{array}{l}0.0256 \\
<.0001 \\
\end{array}$ & $\begin{array}{r}-0.0260 \\
<.0001 \\
\end{array}$ & $\begin{array}{l}0.0138 \\
<.0001 \\
\end{array}$ \\
\hline$M V$ & & & & 1 & $\begin{array}{r}-0.1906 \\
<.0001\end{array}$ & $\begin{array}{l}0.2286 \\
<.0001\end{array}$ \\
\hline$L E V$ & & & & & 1 & $\begin{array}{l}0.0167 \\
<.0001\end{array}$ \\
\hline$R O E$ & & & & & & 1 \\
\hline$N G E$ & & & & & & \\
\hline BETA & & & & & & \\
\hline Coverage & & & & & & \\
\hline$D \_E P S$ & & & & & & \\
\hline D_PRICE & & & & & & \\
\hline
\end{tabular}

\begin{tabular}{|c|c|c|c|c|c|c|}
\hline & $N G E$ & BETA & Coverage & $D_{-} E P S$ & D_PRICE & KOSPI \\
\hline \multirow{2}{*}{$\operatorname{CAR}_{(-1,1)}$} & -0.0110 & 0.0106 & 0.0292 & 0.0291 & 0.0526 & 0.0152 \\
\hline & $<.0001$ & $<.0001$ & $<.0001$ & $<.0001$ & $<.0001$ & $<.0001$ \\
\hline \multirow{2}{*}{$U p_{d u m}$} & 0.0145 & 0.0056 & 0.0027 & 0.0276 & 0.1216 & -0.0044 \\
\hline & $<.0001$ & 0.0013 & 0.1213 & $<.0001$ & $<.0001$ & 0.0111 \\
\hline \multirow{2}{*}{ Down $_{d u m}$} & 0.0223 & 0.0074 & -0.0184 & -0.0533 & -0.0821 & -0.0167 \\
\hline & $<.0001$ & $<.0001$ & $<.0001$ & $<.0001$ & $<.0001$ & $<.0001$ \\
\hline \multirow{2}{*}{ ChaeAff dum $_{\text {dut }}$} & -0.0174 & -0.0122 & 0.0183 & 0.0058 & 0.0007 & 0.0234 \\
\hline & $<.0001$ & $<.0001$ & $<.0001$ & 0.0004 & 0.6547 & $<.0001$ \\
\hline \multirow{2}{*}{$M V$} & -0.1687 & 0.0053 & 0.6866 & 0.0481 & 0.0564 & 0.4882 \\
\hline & $<.0001$ & 0.0023 & $<.0001$ & $<.0001$ & $<.0001$ & $<.0001$ \\
\hline \multirow{2}{*}{$L E V$} & -0.0052 & -0.0250 & -0.1115 & -0.0149 & -0.0242 & -0.2608 \\
\hline & 0.0029 & $<.0001$ & $<.0001$ & $<.0001$ & $<.0001$ & $<.0001$ \\
\hline \multirow{2}{*}{$R O E$} & -0.6855 & -0.0655 & 0.2561 & 0.0849 & 0.0567 & 0.0411 \\
\hline & $<.0001$ & $<.0001$ & $<.0001$ & $<.0001$ & $<.0001$ & $<.0001$ \\
\hline \multirow{2}{*}{$N G E$} & 1 & 0.1358 & -0.1618 & -0.0699 & -0.0360 & -0.1506 \\
\hline & & $<.0001$ & $<.0001$ & $<.0001$ & $<.0001$ & $<.0001$ \\
\hline \multirow{2}{*}{ BETA } & & 1 & 0.0876 & -0.0178 & 0.0028 & -0.2378 \\
\hline & & & $<.0001$ & $<.0001$ & 0.1032 & $<.0001$ \\
\hline \multirow{2}{*}{ Coverage } & & & 1 & 0.0389 & 0.0340 & 0.1927 \\
\hline & & & & $<.0001$ & $<.0001$ & $<.0001$ \\
\hline \multirow{2}{*}{$D \_E P S$} & & & & 1 & 0.1771 & 0.0340 \\
\hline & & & & & $<.0001$ & $<.0001$ \\
\hline \multirow{2}{*}{ D_PRICE } & & & & & 1 & 0.0234 \\
\hline & & & & & & $<.0001$ \\
\hline
\end{tabular}




\subsection{Empirical Results}

Table 4 displays the results of testing of Hypothesis 1 representing differences in short-term stock returns between recommendations. It reports the results of the multivariate testing of Hypothesis 1 based on the estimation in Equation (3). The dependent variable in the model is $C A R_{(-1, l)}$, and the key independent variables are $U p_{\text {dum }}$, and Down dum. The results are as follows (Table 4).

In the second column of Table 4, the t-statistics of $U p_{d u m}$ and Down dum are $7.54(\mathrm{p}=0.01)$ and $-2.18(\mathrm{p}=0.05)$, respectively. This indicates that stock returns after an upward change are significantly higher than those in which the "Buy" recommendation remains the same. Returns after downward changes are significantly lower than those in which the "Buy" recommendation remains the same. In the third column of Table 4, the t-statistics of $U p_{d u m}$ and Down dum are $2.50(\mathrm{p}=0.05)$ and $-9.64(\mathrm{p}=0.01)$, respectively. Thus, similar results are observed within the "Hold" recommendation subset. Therefore, even the same stock recommendations may have different informational content depending on the direction of change in the recommendation (upward or downward). This finding supports Hypothesis 1.

In Table 5, using the interaction term, additional price reactions for Chaebol-affiliated analysts and best analysts are investigated.

Table 4. Results of multiple regression analyses (for testing $\mathrm{H} 1$ )

\begin{tabular}{|c|c|c|c|c|c|c|c|c|c|c|}
\hline \multicolumn{11}{|c|}{$\begin{aligned} \text { CAR }_{(-1,1)} & =a_{0}+a_{1} U p_{d u m}+a_{2} \text { Down }_{d u m}+a_{3} M V+a_{4} L E V+a_{5} R O E+a_{6} N G E+a_{7} \text { BETA }+a_{8} \text { Coverage }+a_{9} D_{-} E P S+a_{9} \\
& D \_P R I C E+a_{10} K O S P I+e\end{aligned}$} \\
\hline \multirow{3}{*}{ Variables } & \multicolumn{10}{|c|}{ Dependent Variable: $C_{A} \boldsymbol{R}_{(-1,1)}$} \\
\hline & \multicolumn{2}{|c|}{ (1) S/Buy } & \multicolumn{2}{|c|}{ (2) Buy } & \multicolumn{2}{|c|}{ (3) Hold } & \multicolumn{2}{|c|}{ (4) U/Weight } & \multicolumn{2}{|c|}{ (5) Sell } \\
\hline & Estimate & T-value & Estimate & T-value & Estimate & T-value & Estimate & T-value & Estimate & T-value \\
\hline Intercept & -0.1101 & $-2.80^{* * *}$ & -0.0508 & $-9.08^{* * *}$ & 0.0183 & $2.56^{* *}$ & 0.0970 & $2.23^{* *}$ & 0.1773 & $2.07^{* *}$ \\
\hline$U p_{d u m}$ & 0.0026 & 0.74 & 0.0055 & $7.54^{* * *}$ & 0.0069 & $2.50^{* *}$ & 0.0031 & 1.20 & & \\
\hline Down $_{d u m}$ & & . & -0.0076 & $-2.18^{* *}$ & -0.0062 & $-9.64^{* * *}$ & -0.0042 & $-2.84^{* * *}$ & -0.0038 & -0.76 \\
\hline$M V$ & 0.0049 & $3.60^{* * *}$ & 0.0018 & $8.55^{* * *}$ & -0.0006 & $-2.26^{* *}$ & -0.0039 & $-2.43^{* *}$ & -0.0081 & $-2.76^{* * *}$ \\
\hline$L E V$ & -0.0002 & -0.60 & 0.0000 & 0.30 & -0.0001 & $-1.96^{* *}$ & 0.0002 & 0.96 & -0.0003 & -0.72 \\
\hline$R O E$ & -0.0073 & -0.72 & 0.0085 & $5.73^{* * *}$ & 0.0033 & $2.33^{* *}$ & -0.0062 & -1.40 & 0.0000 & 0.00 \\
\hline$N G E$ & 0.0015 & 0.39 & 0.0022 & $3.60^{* * *}$ & 0.0002 & 0.43 & -0.0002 & -0.11 & -0.0006 & -0.12 \\
\hline BETA & 0.0010 & 0.40 & 0.0007 & $1.91^{*}$ & 0.0001 & 0.23 & -0.0002 & -0.05 & -0.0174 & $-2.12^{* *}$ \\
\hline Coverage & -0.0002 & -1.02 & 0.0000 & 0.26 & -0.0001 & $-3.21^{* * *}$ & 0.0002 & 1.19 & 0.0002 & 1.02 \\
\hline$D \_E P S$ & 0.0159 & $1.63^{*}$ & 0.0113 & $11.18^{* * *}$ & 0.0037 & $4.05^{* * *}$ & 0.0040 & $1.63^{*}$ & 0.0024 & 0.36 \\
\hline D_PRICE & 0.0408 & $3.75^{* * *}$ & 0.0351 & $20.65^{* * *}$ & 0.0191 & $6.86^{* * *}$ & 0.0004 & 0.03 & 0.0045 & 0.10 \\
\hline$\overline{K O S P I}$ & -0.0040 & $-1.99^{* *}$ & -0.0016 & $-5.55^{* * *}$ & -0.0012 & $-3.70^{* * *}$ & 0.0012 & 0.63 & -0.0014 & -0.42 \\
\hline Year dummv $_{\text {dum }}$ & \multicolumn{2}{|c|}{ Included } & \multicolumn{2}{|c|}{ Included } & \multicolumn{2}{|c|}{ Included } & \multicolumn{2}{|c|}{ Included } & \multicolumn{2}{|c|}{ Included } \\
\hline Ind dummy & \multicolumn{2}{|c|}{ Included } & \multicolumn{2}{|c|}{ Included } & \multicolumn{2}{|c|}{ Included } & \multicolumn{2}{|c|}{ Included } & \multicolumn{2}{|c|}{ Included } \\
\hline Adj. $\mathrm{R}^{2}$ & \multicolumn{2}{|c|}{0.02753} & \multirow{2}{*}{\multicolumn{2}{|c|}{0.00693}} & \multicolumn{2}{|c|}{0.00561} & \multicolumn{2}{|c|}{0.0363} & \multicolumn{2}{|c|}{0.07939} \\
\hline Obs. & \multicolumn{2}{|c|}{2,412} & & & \multicolumn{2}{|c|}{92,734} & \multicolumn{2}{|c|}{3,234} & \multicolumn{2}{|c|}{454} \\
\hline
\end{tabular}


Table 5. Results of multiple regression analyses (for testing $\mathrm{H} 2$ )

\begin{tabular}{|c|c|c|c|c|c|c|c|c|c|c|}
\hline \multicolumn{11}{|c|}{ 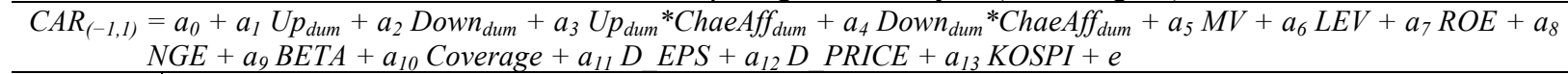 } \\
\hline \multirow{3}{*}{ Variables } & \multicolumn{10}{|c|}{ Dependent Variable: CAR $_{(-1,1)}$} \\
\hline & \multicolumn{2}{|c|}{ (1) S/Buy } & \multicolumn{2}{|c|}{ (2) Buy } & \multicolumn{2}{|c|}{ (3) Hold } & \multicolumn{2}{|c|}{ (4) U/Weight } & \multicolumn{2}{|c|}{ (5) Sell } \\
\hline & Estimate & T-value & Estimate & T-value & Estimate & T-value & Estimate & T-value & Estimate & T-value \\
\hline Intercept & -0.1108 & $-2.80^{* * *}$ & -0.0508 & $-9.07^{* * *}$ & 0.0184 & $2.57^{* *}$ & 0.0970 & $2.23^{* *}$ & 0.1774 & $2.07^{* *}$ \\
\hline$U p_{d u m}$ & 0.0031 & 0.88 & 0.0054 & $7.35^{* * *}$ & 0.0070 & $2.52^{* *}$ & 0.0031 & 1.20 & & \\
\hline Down $_{\text {dum }}$ & & & -0.0070 & $-2.04^{* *}$ & -0.0063 & $-9.81^{* * *}$ & -0.0042 & $-2.84^{* * *}$ & -0.0038 & -0.75 \\
\hline $\begin{array}{l}\text { Up dum } \\
\text { ChaeAff } \\
\text { dum }\end{array}$ & 0.0525 & $2.62^{* * *}$ & 0.0136 & $2.12^{* *}$ & 0.0248 & $8.75^{* * *}$ & & & & \\
\hline $\begin{array}{l}\text { Down }_{\text {dum }} * \\
\text { ChaeAff }_{\text {dum }}\end{array}$ & & & -0.1156 & $-1.39^{*}$ & -0.0117 & $-1.62^{*}$ & & & -0.0021 & -0.35 \\
\hline$M V$ & 0.0050 & $3.59^{* * *}$ & 0.0018 & $8.54^{* * *}$ & -0.0006 & $-2.27^{* *}$ & -0.0039 & $-2.43^{* *}$ & -0.0081 & $-2.76^{* * *}$ \\
\hline$L E V$ & -0.0002 & -0.63 & 0.0000 & 0.29 & -0.0001 & $-1.95^{*}$ & 0.0002 & 0.96 & -0.0003 & -0.71 \\
\hline$R O E$ & -0.0076 & -0.76 & 0.0085 & $5.73^{* * *}$ & 0.0033 & $2.32^{* *}$ & -0.0062 & -1.40 & 0.0000 & 0.00 \\
\hline$N G E$ & 0.0013 & 0.34 & 0.0022 & $3.63^{* * *}$ & 0.0002 & 0.43 & -0.0002 & -0.11 & -0.0006 & -0.13 \\
\hline BETA & 0.0011 & 0.45 & 0.0007 & $1.93^{*}$ & 0.0001 & 0.20 & -0.0002 & -0.05 & -0.0174 & $-2.12^{* *}$ \\
\hline Coverage & -0.0001 & -0.99 & 0.0000 & 0.26 & -0.0001 & $-3.22^{* * *}$ & 0.0002 & 1.19 & 0.0002 & 1.02 \\
\hline$D \_E P S$ & 0.0166 & $1.71^{*}$ & 0.0113 & $11.21^{* * *}$ & 0.0037 & $4.01^{* * *}$ & 0.0040 & $1.63^{*}$ & 0.0024 & 0.36 \\
\hline D_PRICE & 0.0434 & $3.93^{* * *}$ & 0.0351 & $20.62^{* * *}$ & 0.0190 & $6.84^{* * *}$ & 0.0004 & 0.03 & 0.0045 & 0.10 \\
\hline KOSPI & -0.0040 & $-1.97^{* *}$ & -0.0508 & $-9.07^{* *}$ & -0.0012 & $-3.70^{* * *}$ & 0.0012 & 0.63 & -0.0014 & -0.41 \\
\hline Year dummv $_{\text {du }}$ & \multicolumn{2}{|c|}{ Included } & \multicolumn{2}{|c|}{ Included } & \multicolumn{2}{|c|}{ Included } & \multicolumn{2}{|c|}{ Included } & \multicolumn{2}{|c|}{ Included } \\
\hline Ind dummy & \multicolumn{2}{|c|}{ Included } & \multicolumn{2}{|c|}{ Included } & \multicolumn{2}{|c|}{ Included } & \multicolumn{2}{|c|}{ Included } & \multicolumn{2}{|c|}{ Included } \\
\hline Adj. $\mathrm{R}^{2}$ & \multicolumn{2}{|c|}{0.02869} & \multicolumn{2}{|c|}{0.00696} & \multicolumn{2}{|c|}{0.00568} & \multicolumn{2}{|c|}{0.0363} & \multicolumn{2}{|c|}{0.0794} \\
\hline Obs. & \multicolumn{2}{|c|}{2,412} & \multicolumn{2}{|c|}{229,700} & \multicolumn{2}{|c|}{92,734} & \multicolumn{2}{|c|}{3,234} & \multicolumn{2}{|c|}{454} \\
\hline
\end{tabular}

In Table 5, the signs of the coefficients of the interaction variables are notable. In the first, second and third columns of Table 5, the t-statistics of $U p_{\text {dum }}{ }^{*}$ ChaeAff dum are significant $2.62(\mathrm{p}=0.01), 2.12(\mathrm{p}=0.05)$ and $8.75(\mathrm{p}=0.05)$ respectively. In second and third colums, the t-statistics of $D_{o w n}$ dum $^{*}{ }^{*}$ ChaeAff dum are significant $-1.39(\mathrm{p}=0.10)$ and $-1.62(p=0.10)$, respectively. This indicates that stock returns after upgraded revisions of Chaebol-affiliated analysts are significantly higher than those of non-Chaebol-affiliated analysts. In addition, stock returns from downgraded revisions of Chaebol-affiliated analysts are significantly lower than those of non-Chaebol-affiliated analysts.

Overall, the results in Tables 4 and 5 support Hypothesis 1 and reject Hypothesis 2. Thus, an upgraded (or downgraded) revision within the same recommendation category is associated with a greater (lower) stock price return. In addition, the information environment (chaebol affiliated analysts) are related to the informational content of analyst reports.

\section{CONCLUSION}

Accurate analysts' reports alleviate information asymmetry between companies and investors by providing accounting information that is useful in investment decision-making for market participants. Investors evaluate the credibility of stock recommendations based on the accuracy of the earnings forecasts of analysts, applying them in the decisionmaking process. Studies of stock recommendations have focused on the informational content of stock recommendations, systematically analyzing the characteristics of recommendations and, to a lesser degree, decisionmaking factors. For most analysts $(90.90 \%)$, when stock recommendations and forecast changes are simultaneously disclosed, a large bias results if analysts fail to consider the magnitude of the market reaction relative to the earnings forecast and stock recommendations. In most previous studies, the informational content of both individual stock recommendations and changes in stock recommendations was investigated. In this study, however, we examine differences in the informational content depending on the stock recommendations of the report released immediately previous to the current report for the same recommendation. This study shows that even the same stock recommendation for different firms in the market may have different informational content depending on the direction of change (upward, downward, or status quo) for the "Buy" and "Hold" recommendations. In addition, two important 
variables, the information environment (chaebol-affiliated-analysts) and analyst individual ability, are related to the informational content of analyst reports.

\section{ACKNOWLEDGEMENTS}

This work was supported by Incheon National University (International Cooperative) Research Grant in 2016.

\section{AUTHOR BIOGRAPHIES}

Youngtae Yoo, Assistant Professor, Dept. of Tax \& Accounting, Incheon National University, 119 Academy-ro, Yeonsu-gu, Incheon 22012, Korea. E-mail: ytae@inu.ac.kr

Hyunjun Park (contact author), Assistant Professor, Dept. of Business Administration, Incheon National University, 119 Academy-ro, Yeonsu-gu, Incheon 22012, Korea. E-mail: sampark@inu.ac.kr

\section{REFERENCES}

Aboody, D., M. E. Barth, and R. Kasznik (1999). Revaluation of fixed assets and future firm performance: evidence from the UK. Journal of Accounting and Economics, 26, 149-178.

Barber, B., R. Lehavy, M. McNichols, and B. Trueman (2001). Can investors profit from the prophets? Security analyst recommendations and stock returns. The Journal of Finance, 56, 531-563.

Beaver, W. (1968). Information content of annual earnings announcements. Journal of Accounting Research (Supplement), 6792.

Clement, M. B. (1999). Analysts forecast accuracy: Do ability, resources, and portfolio complexity matter? Journal of Accounting and Economics, 27, 285-303.

Collins, DW. and SP. Kothari (1989). An analysis of intertemporal and cross-sectional determinants of earnings response coefficients. Journal of Accounting and Economics, 11, 143-181.

Elton. EJ., MJ. Gruber, and S. Grossman (1986). Discrete expectational data and portfolio performance. The Journal of Finance, $41,699-713$.

Hayn, C. (1995). The information content of losses. Journal of Accounting and Economics, 20, 125-153.

Jacob, J., T. Z. Lys, and M. A. Neale (1999). Expertise in forecasting performance of security analysts. Journal of Accounting and Economics, 28, 51-82.

Jegadeesh, N. and W. Kim (2010). Do analysts herd? An analysis of recommendations and market reactions. The Review of Financial Studies, 23, 901-937.

Jeong, SW. and TK. Lim (2005). 'The effect of earnings persistence on analysts' forecast error and accuracy. Korean Accounting Review, 30, 209-235.

Kho, BC. And JW. Kim (2007). Earnings forecast accuracy and recommendation profitability of the analysts in Korea. Journal of Korean Securities Association, 36, 1009-1047.

Kim, JD., HT. An, and SM. Bae (2013). Analysis of firm-specific characteristics that affect the stock market response to the disclosure of asset revaluation. Korea International Accounting Review, 48, 1-28.

Kim, DS. and SS. Eum (2006). The impact of analysts' revisions in their stock recommendation and target prices on stock prices. Journal of Korean Securities Association, 35, 75-108.

Lee, WH. and SM. Choi (2003). The effect of changes in analysts' investment recommendation ranking on stock returns and trading volumes. Journal of Korean Securities Association, 32, 1-44.

Leone, AJ. and JS. Wu (2007). What does it take to become a superstar? Evidence from institutional investor rankings of financial analysts. Working paper. Simon school of business.

Mikhail, MB., BR. Walther, and RH. Willis (1997). Do security analysts improve their performance with experience? Journal of Accounting Research, 35, 131-157.

Stickel, S. (1992). Reputation and performance among security analysts. The Journal of Finance, 47(5), 1811-1836.

Yoo, YT. and MJ. Kang (2015). "No Response" instead of stock recommendations: Evidence from Korea. The Journal of Applied Business Research, 31(4), 1563-1578.

Womack, KL. (1996). Do brokerage analysts' recommendations have investment value? The Journal of Finance, 54, $137-157$. 